\title{
DESIGN OF SOLAR TRACKING SYSTEM
}

\author{
Faissal Abdel-Hady ${ }^{\# 1}$ \\ \# Chemical \& Materials Engineering Dept., Faculty of Engineering, \\ King Abdulaziz University, Jeddah Saudi Arabia \\ ${ }^{1}$ faissalhady@gmail.com
}

\begin{abstract}
There have been a lot of research on how to improve the performance of parabolic trough collectors for the past few decades. One way of doing so is the incorporation of solar tracking system to the design of parabolic trough collector. Even though various approach have been established on how to improve its design and better way of incorporating it with parabolic trough collector but there are still a lot to be done in the aspect of the design of highly efficient algorithm, ease of control, size of equipment and use of readily available material which will eventually have an impact on the overall design cost. Therefore, this paper worked on the design of a horizontal single axis North- South solar tracking algorithm. The algorithm was implemented with the use of national instrument LabView ${ }^{\circledR} 14$ software programme linked with Galil DMC-3x01x single axis motion controller. The Galil DMC-3x01x motion controller in collaboration with DC motor, encoder, etc. was used to drive the parabolic trough collector in order to follow the sun from sunrise to sunset. Error estimation was carried out in order to ascertain the performance of the solar tracker. The designed algorithm was able to track the sun effectively from sunrise to sunset with minimal error obtained.
\end{abstract}

Keywords: North- South solar tracking algorithm, Renewable Energy, motion controller.

\section{INTRODUCTION}

The output power generated by highly-concentrated solar thermal and photovoltaic systems is directly associated to the quantity of solar energy harnessed by the system, and this can be achieved by tracking the sun's location with a great amount of precision [1].

The angle of the sun varies between different hours of the day and the different seasons of a year and for this motive, some power plants use solar tracking systems to sustain a high level of efficiency [2]. A solar system with no tracking are positioned with an inclined angle, so that in the northern hemisphere, it is faced southward and their location cannot be altered during the day. Of course, it's likely to change their angular location in different seasons in order to obtain an enhanced output.

A Solar Tracker is a device that accommodates solar installation in such a way that it tracks the motion of the sun across the sky making sure that the maximum amount of solar rays strikes the installation during the day and by so doing increases its efficiency/performance [3]. The first programmed solar tracking systems was introduced by McFee in 1975 [1] where algorithm was established to calculate total received power and flux density dissemination in a central receiver solar power system [5]. Also, Semma and Imamru used a simple microprocessor to adaptively regulate the locations of the solar collectors in a photovoltaic concentrator such that they are in the direction of the sun at every moment [6].

There are various types of solar trackers, such as single-axis and dual-axis trackers. Degree of latitude, size of Installation, local weather, and electrical requirements are all key factors that can determine the type of solar tracker that is best appropriate for a particular solar installation. The solar tracker tend to increase the direct exposure of solar systems to sunlight as much as 10 to $25 \%$ depending on the geographic location of the tracking system [4].

The single-axis trackers basically revolve about a unique axis, azimuthally moving from east to west during the course of the day while Double-axis (dual-axis) trackers alternate both east to west and zenithally (vertically). The methods of drive could be active, passive or chronological tracking. The active trackers employs motors and gear trains to direct the tracker as ordered by a controller reacting to the solar direction, the passive solar trackers employs a low boiling point compressed gas fluid that is compelled to one side or the other (by solar heat creating gas pressure) to cause the tracker to move in reaction to an imbalance and the Chronological solar Tracker counters the earth's rotation by rotating at an equal proportion as the earth, but in the reverse direction [3].

The various elements that makes up of a tracking systems are the control unit, sun tracking algorithm, Drive mechanism/transmission, Sun tracking algorithm, Sensing devices (pyranometers, Limit switches, motor encoder, inclinometer and an anemometer etc.) [11]. 
There had been a lot of work carried out on tracking system but starting from the recent studies, in 1997, Stone and Sutherland [7] presented a multiple tracking measurement system which consist of more than 100 heliostats for tracking the sun's location at an interval of 1 hour from early part of the morning to later in the evening. Khalifa and Al-Mutawalli [8] in 1998 designed a two-axis sun tracking system to boost the thermal operation of a compound parabolic concentrator. Development of a sun tracking system was carried out by Yousef [9] in which the nonlinear dynamics of the tracking device were controlled with the use of a fuzzy logic control procedure applied on a PC and maintained by an interfacing card comprising of a sensor data acquisition function, motor driving circuits, signal conditioning circuits and serial communications.

In 2004, Roth et al. [10] designed and constructed a sun tracking system with the use of pyrheliometer to evaluate the direct solar radiation. It was controlled by a closed loop servo system comprising of a four-quadrant photo-detector to determine the sun's location and two little DC motors to control the instrument platform so that the sun's image stayed at the centre of the four-quadrant detector always. Moving down to the most recent studies, Bin-Juine et al. [13] developed and tested a single-axis 3 positions sun tracking PV in Taipei (Taiwan) and they came up with increase in energy generation of $39 \%$ for a particular day. Yingxue at al. [14] worked on a dual-axis multipurpose solar tracker. The tracker uses declination mounting-system on both flat photovoltaic and concentrating solar power system with its axis positioned in an east-west direction. They compared the average energy efficiency of the system with the one that has a fixed PV and concluded that the one with the tracking system is $23.6 \%$ more efficient than that of fixed PV. Similar to the work of [14], Laughlin et al. [15] designed a low profile two-axis solar tracker which was tested on a concave mirror by measuring its receiver temperature. The tracker concept is based on translational motion which is composed of two coplanar and perpendicular linear actuator attached to a single linkage arm and pivots. Fabienne et al. [16] worked on error characterization on a single axis solar tracker by adapting to the International standard IEC 62817 testing procedure for photovoltaic tracker. The optical losses due to tracking error (which was obtained to be $\pm 0.4^{\circ}$ ) was calculated by using incidence angle modifier obtained with ray-tracing simulation. Even though there has been various work done on solar trackers there are limitations of solar trackers for parabolic trough collectors especially in the aspect of algorithm generation and design for the single axis tracking.

In order to improve on the efficiency and performance of the parabolic trough, it is essential to harness maximally the amount of irradiation coming from the sun. Therefore, presented in this study is the Algorithm, design and experimentation of a single axis solar tracker on parabolic trough collector. Horizontal tracking axis positioned in the North-south direction was adopted. The implementation of the design was assembled from components that are readily available in order to encourage a low cost solution and less specialized parts.

\begin{tabular}{|llll|}
\hline Nomenclature & & & \\
$f$ & Focal length of parabola & $\begin{array}{l}\text { Greek } \\
\text { symbols }\end{array}$ & \\
$h$ & Height of parabola & $\theta_{z}$ & Zenith angle \\
& & $\omega_{s}$ & Hour angle at sunset \\
$Y$ & y-axis of parabola & $\delta$ & Declination angle \\
$X$ & X-axis of parabola & $\alpha$ & Altitude angle \\
$S$ & Length of parabola arc & $\omega$ & Hour Angle \\
$W$ & Width of parabola & $\emptyset$ & Latitude angle. \\
$A_{c}$ & Collector aperture area & $\theta$ & Incidence angle \\
$E_{b}$ & Irradiation & $\rho$ & Tracking angle \\
$L$ & Length of the parabolic trough / & Acronyms & \\
& receiver tube & $P T C$ & Parabolic trough collector \\
$D$ & Receiver tube outer diameter & $C A D$ & Computer aided design \\
$A$ & Azimuth angle & $C S P$ & Concentrated solar power \\
& & $E O T$ & Equation of time \\
$t_{s}$ & Solar time & $L C T$ & Local clock time \\
$C$ & Geometric concentration ratio & $L C$ & Longitude correction \\
& & $r p m$ & Revolutions per minute \\
& & $P V$ & Photo voltaic \\
\hline
\end{tabular}




\section{DESIGN}

In order to be able to collect energy from the sun, it is required to calculate the position of the sun relative to the collection device which in our case is a six series connected PTC. The arrangement and installation of the PTC's are as shown in Fig 1. The development of the necessary equations using a unique vector method and the solar tracking elements/component that makes up the whole system configuration are summarized below.

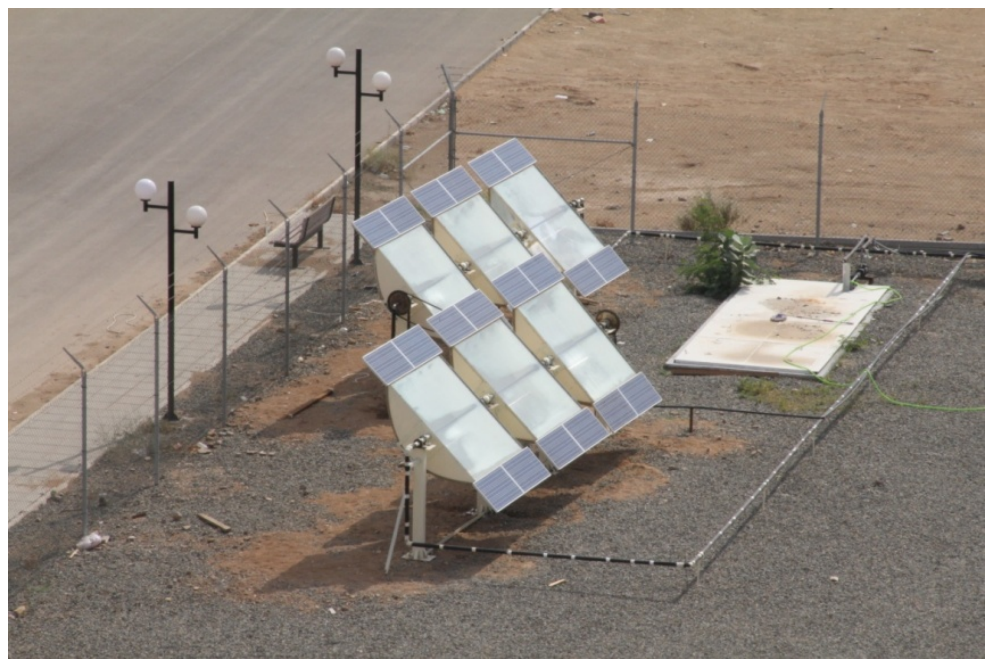

Figure 1 Arrangement of a six series connected PTC

\section{A. Geographical location}

The research was carried out in Jeddah, Makkah province Saudi Arabia. The geographical coordinate of the location is $21^{\circ} 32^{\prime} 36^{\prime \prime}$ north latitude and $39^{\circ} 10^{\prime} 22^{\prime \prime}$ East Longitude. Jeddah features a humid desert/arid weather which retains its hot temperature in winter at a range of $15^{\circ} \mathrm{C}$ at dawn to $28^{\circ} \mathrm{C}$ at noon. While its summer temperature is around $43^{\circ} \mathrm{C}$ at noon to $30^{\circ} \mathrm{C}$ in the evening [16].

\section{B. Sun Tracking Algorithm}

The six series connected PTC's axis of rotation is positioned or oriented in the horizontal north-south direction while tracking the sun from east to west during the day and returns back to east (home position) at sunset. Even though the collectors can be oriented in the horizontal east-west direction, it has the disadvantage of lower performance during the early (morning) and late (evening) hours of the day due to cosine loss [18] which makes the north-south positioning more desirable in this design. Moreover, more energy can be harvested by the horizontal north-south tracking during the summer than that of the horizontal east-west orientation which complements our geographical location and the essence of the whole system design.

The algorithm is designed based on a closed loop system. The mathematical formulae used in the design of the algorithm are summarised below.

1) Hour angle

The movement of the earth about its axis can be described with Hour angle. As it can be seen in the Fig 2 below, Hour angle is regarded as the angle between the meridian parallel to sun rays and the meridian containing the observer. The hour angle may be measured in degrees or time with 24 -hour clock equal to $360^{\circ}$ and it increases by $15^{\circ}$ in every 1-hour. By using the concept of solar time due to the consideration of $24 \mathrm{hr}$ clock and to completely predict the sunrays direction relative to a point on the earth surface. An expression of the hour angle from solar time can be given as:

$$
\omega=15\left(t_{s}-12\right) \quad(\text { Degrees })
$$

2) Declination angle $(\delta)$

The angle formed between the earth's equatorial plane and the line drawn in a manner at which it passes the centre of the earth and the sun is regarded as declination angle. The declination angle is depicted in Fig 2 below. Declination angle varies from $+23.45^{\circ}$ to $-23.45^{\circ}$ during summer (about June 21st) and winter (December 22nd) respectively and when the declination angle is $0^{\circ}$ it represents either fall or spring period. With September 23rd indicating the beginning of fall and March 22nd indicating the beginning of spring. Declination angle can be expressed as

$$
\delta=\sin ^{-1}(0.39795 \cos [0.98563(N-173)])
$$




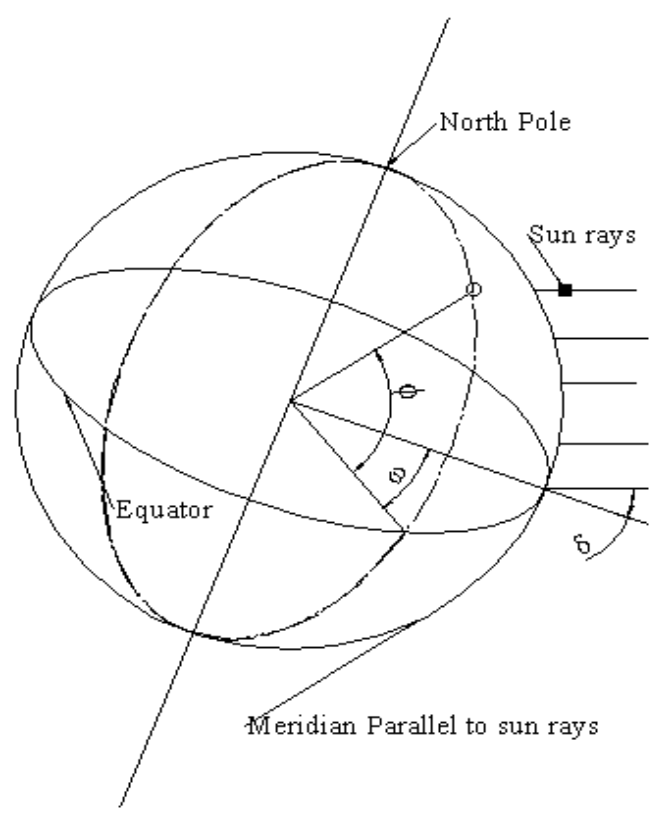

Figure 2 Hour angle $(\omega)$, Declination angle $(\delta)$ and Latitude angle $(\phi)$ during the Earth's rotation about its polar axis.

3) Latitude angle $(\varnothing)$

Latitude angle can also be defined using Fig 3.2 above as the angle between a line drawn from a point on the earth's surface to the centre of the earth and the earth's equatorial plane. At zero degree latitude an equator is formed and this is where the equatorial plane and the surface of the earth intersect. There are other latitude angles of interest which are tropic of cancer $(+23.45$ degrees latitude), Tropic of Capricorn ( -23.45 degrees latitude), Arctic Circle (66.55 degrees latitude) and Antarctic Circle (-66.5 degrees latitude) which are formed as a result of the intersection of a perpendicular to the earth-sun line.

4) Sunrise (SRT), Sunset time (SST) and Solar noon (SN)

For the design of tracking algorithm it is imperative to be able to predict the time and location of sunrise and sunset and the length of the day.

In order to estimate the SST and SSR which will enable us also to determine the length of the day, it is required to determine the hour angle for both SST and SRT. Therefore, for a flat local horizon the altitude angle is zero at sunset (assuming that the solar altitude at sunset is equal to horizon angle) and the hour angle at sunset $\left(\omega_{\mathrm{s}}\right)$ can be given as

$$
\omega_{s}=\cos ^{-1}(-\tan \delta \tan \emptyset) \quad \text { (degrees) }
$$

Note: If $(\tan \delta \tan \emptyset) \geq 1$, then there is no sunset for that particular day. While there is no sunrise for that particular day if $(\tan \delta \tan \emptyset) \leq-1$.

The hour of daylight can therefore be estimated as

$$
\text { Hours of daylight }=\frac{2 \omega_{s}}{15} \quad \text { (hours) }
$$

Solar noon (SN) can be estimated from both SST and SRT as

$$
\mathrm{SN}=\mathrm{SRT}+\left(\frac{\mathrm{SST}-\mathrm{SRT}}{2}\right)
$$

5) Equation of time (EOT)

The difference between local clock time and solar time is what is called EOT, it is essential for the determination of tracking algorithm with requirement of high level of accuracy in order to fulfil the control requirement of the PTC. According to Lamm [17], EOT can be given as

$$
\text { EOT }=60 \sum_{k=0}^{5}\left[A_{k} \cos \left(\frac{360 k N}{365.25}\right)+B_{k} \sin \left(\frac{360 k N}{365.25}\right)\right] \quad \text { minutes }
$$

Where $\mathrm{N}$ is the number of days, $\mathrm{A}_{\mathrm{k}}$ and $\mathrm{B}_{\mathrm{k}}$ are coefficients of the equation. 
Table I. COEFFICIENTS OF THE EQUATION OF TIME[22]

\begin{tabular}{|c|c|c|}
\hline$\underline{\boldsymbol{K}}$ & $\underline{\boldsymbol{A}_{\underline{k}}(\mathbf{h r})}$ & $\underline{\boldsymbol{B}_{\underline{k}}(\mathbf{h r})}$ \\
\hline 0 & $2.0870 \times 10^{-4}$ & 0 \\
\hline 1 & $9.2869 \times 10^{-3}$ & $1.2229 \times 10^{-1}$ \\
\hline 2 & $5.2258 \times 10^{-2}$ & $1.5698 \times 10^{-1}$ \\
\hline 3 & $1.3077 \times 10^{-3}$ & $5.1602 \times 10^{-3}$ \\
\hline 4 & $2.1867 \times 10^{-3}$ & $2.9823 \times 10^{-3}$ \\
\hline 5 & $1.5100 \times 10^{-4}$ & $2.3463 \times 10^{-4}$ \\
\hline
\end{tabular}

6) Local clock time (LCT)/ Longitude correction (LC)

In as much that the local clock time is of little concern in the design of solar tracking system it is very important in time conversion analysis. The knowledge of local standards, the day of the year and location is a requirement for conversion between solar time and clock time. The relationship between LC, EOT and LCT can be given as

$$
L C T=t_{s}-\frac{E O T}{60}+L C+D \quad \text { (hours) }
$$

And longitude correction can be given as

$$
L C=\frac{\text { (local longitude })- \text { (longitude of standard time zone meridian) }}{15} \text { (hours) }
$$

$\mathrm{D}$ is equal to 1 (hour) if the location is in a region where daylight savings time is currently in effect, or zero otherwise.

7) Zenith angle $\left(\theta_{z}\right)$ and Altitude angle $(\alpha)$

The angle formed between the central ray of the sun and the vertical plane can be regarded as solar zenith angle while the altitude angle is the complement of the solar Zenith angle. Fig. 3 shows the relationship between zenith angle, altitude angle and azimuth angle for better understanding. The equation of zenith and altitude angle can be given as:

$$
\begin{gathered}
\alpha=\sin ^{-1}(\sin \delta \sin \emptyset+\cos \delta \cos \omega \cos \emptyset) \quad \text { (degrees) } \\
\theta_{z}=90-\alpha
\end{gathered}
$$

Where $\emptyset$ is the latitude angle and it is the angle formed when a line is drawn from a point on the earth surface to the centre of the earth and its equatorial plane. It is of optimum importance to be able to calculate the zenith angle and altitude angle at any location at any given time for solar tracking design.

8) Solar Azimuth angle (A)

From Fig. 3, solar azimuth angle (A) can be measured from due North in a clockwise direction. It should be noted that there are other ways of measuring the Azimuth angle rather than from the north-pointing coordinate and in a clockwise direction. The solar azimuth angle can be calculated in two ways and the equations are given as:

Method 1:

Where if:

$$
A^{\prime}=\sin ^{-1}\left(\frac{-\cos \delta \sin \omega}{\cos \alpha}\right) \quad \text { (degrees) }
$$

$$
\cos \omega \geq\left(\frac{\tan \delta}{\tan \varnothing}\right), \text { then } \mathrm{A}=180^{\circ}-\mathrm{A}^{\prime}
$$

Otherwise:

$$
\cos \omega<\left(\frac{\tan \delta}{\tan \varnothing}\right), \text { then } \mathrm{A}=360^{\circ}+\mathrm{A}^{\prime}
$$

Method 2 


$$
\begin{aligned}
& A^{\prime \prime}=\cos ^{-1}\left(\frac{\sin \delta \cos \emptyset-\cos \delta \cos \omega \sin \emptyset}{\cos \alpha}\right) \\
& \text { Where if: } \quad \sin \omega>0 \quad \text { then } A=360^{\circ}-A^{\prime \prime} \\
& \text { Otherwise } \quad \sin \omega \leq 0 \text { and } A=A^{\prime \prime}
\end{aligned}
$$

The sun's position in the sky can easily be determined in terms of date, time and location since azimuth angle and altitude angle equations are gotten in terms of latitude, declination and hour angle.

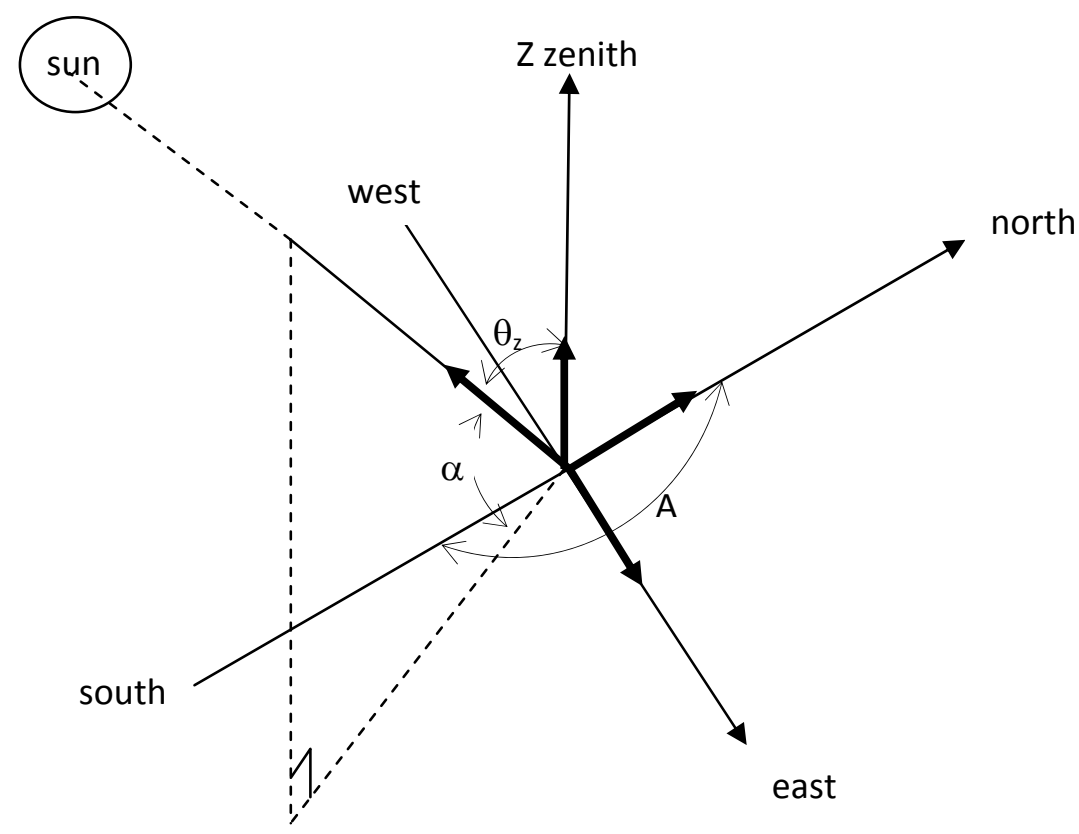

Figure 3 The Altitude angle $(\alpha)$, Zenith angle $\left(\theta_{z}\right)$ and Azimuth angle (A) of an Earth surface coordinate system.

9) Incidence angle $(\theta)$ and tracking angle $(\rho)$

Angle of incidence and tracking angle are essential in the design of solar energy system. Since the radiation of the sun that could reach a collector aperture is reduced by the cosine effect of incidence angle, therefore the determination of the angle between the vector perpendicular to the aperture of the collector and the rays of the sun is regarded as incidence angle. The incidence angle for horizontal single axis north-south tracking can be given as

$$
\theta=\cos ^{-1}\left(\sqrt{1-\cos ^{2}(\alpha) \cos ^{2}(A)}\right)
$$

The tracking angle at the other hand is the amount of rotation required to align the axis of the collector aperture normal to the central ray of the sun. At least one axis of the collector aperture is required to be aligned to the sun's central ray. With this in mind, horizontal single axis north- south tracking is being adopted in this paper. The tracking angle for north-south horizontal tracking can be given as

$$
\rho=\tan ^{-1}\left(\frac{\sin A}{\tan \alpha}\right)
$$

\section{B. Sun tracking system}

Solar tracking system plays an important role in the process of following the sun's trajectory (i.e. the normal beam of the sun) throughout the course of the day which results in the increase in performance of the collector. Therefore it is highly imperative to provide a high accuracy system of tracking. The elements/ components that makes up the sun tracking system are summarized below

1) Drive mechanism/transmission

Since the sun's position have been ascertained through the development of algorithm it is necessary to ensure that the solar collector system utilizes this algorithm to follow the sun so as to produce solar energy during the day. Therefore, the drive mechanism employed for the design is a chain drive mechanism. The PTC's are connected in such a way that three PTC are arranged as one unit while the remaining three are arranged as another unit and then the two units are connected together by chain drive to a dual shaft geared DC motor as shown in Fig. 5 bellow. The DC motor rotates the collectors using a speed reduction transmission system (worm speed reducer) with a gear ratio of 1:100 while the rotational speed of the DC motor used was $1800 \mathrm{rpm}$. The diagram of the drive mechanism/transmission system can be seen in Fig. 5. 


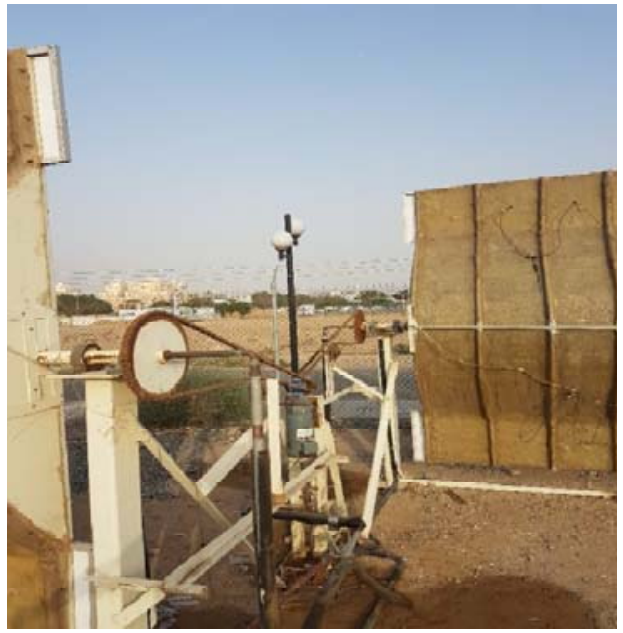

Figure 4 A chain drive mechanism system

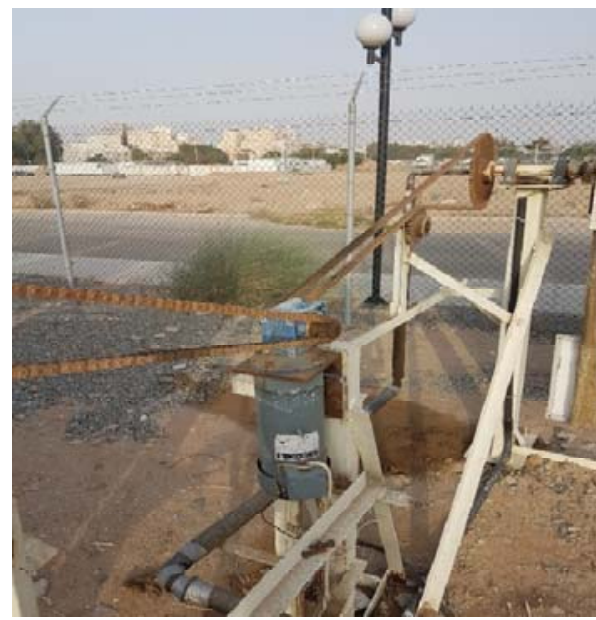

Figure $5 \mathrm{~A}$ chain drive mechanism system

The gear reduction according to the number of driven and driving teeth of the chain drive mechanism can be given as

$$
\text { Gear reduction }=\frac{\text { driven gear teeth }}{\text { driving gear teeth }}=\frac{60}{9}=6.667
$$

So, the total speed reduction from the motor to the collectors is 666.7 which gives enough torque to drive the 6 collectors with a DC motor of $1 \mathrm{KW}$ power.

2) Control system, PV and Battery storage unit

The control system is made up of four units as shown by Fig.6. The computer unit utilizes the designed algorithm to calculate the position of the DC motor at certain time and sends a command to the motion control card (Galil DMC-3x01x single axis motion controller).

The motion control card is used to control the position of the motor by driving the DC motor. This is done by counting the steps of the motor until it gets to a specified position before it stops. It then sends a feedback to the computer unit to wait for further command.

The motion control parameters (i.e. the normal PID parameters) for the system are selected to avoid any overshoot or oscillation of the PTC during tracking. Once the normal PID parameters have been stored by the motion control card and the position of the DC motor have been obtained by the motion control unit, it calculates the speed profile including the acceleration, constant, and deceleration (starting and constant speed) and deceleration of the obtained position and send it as an analog command to the power amplifier. The power amplifier receives the analog signal from the motion control card and converts it to pulse width modulated signal and send it to the encoder of the DC motor. The encoder sends back its position to the motion control card as a feedback signal for motion command termination. 
The motion control card unit (Galil DMC-3x01x single axis motion controller) is shown in Fig. 6 while the 25A20 PWM servo amplifier connected to choke coil and contactor are shown in Fig. 7. The choke coil serves as a safety barrier in order prevent a back feed high voltage spike from damaging the amplifier due to stoppage of the DC motor while the contactor serves as the connector between the battery and the amplifier by supplying power to the it.

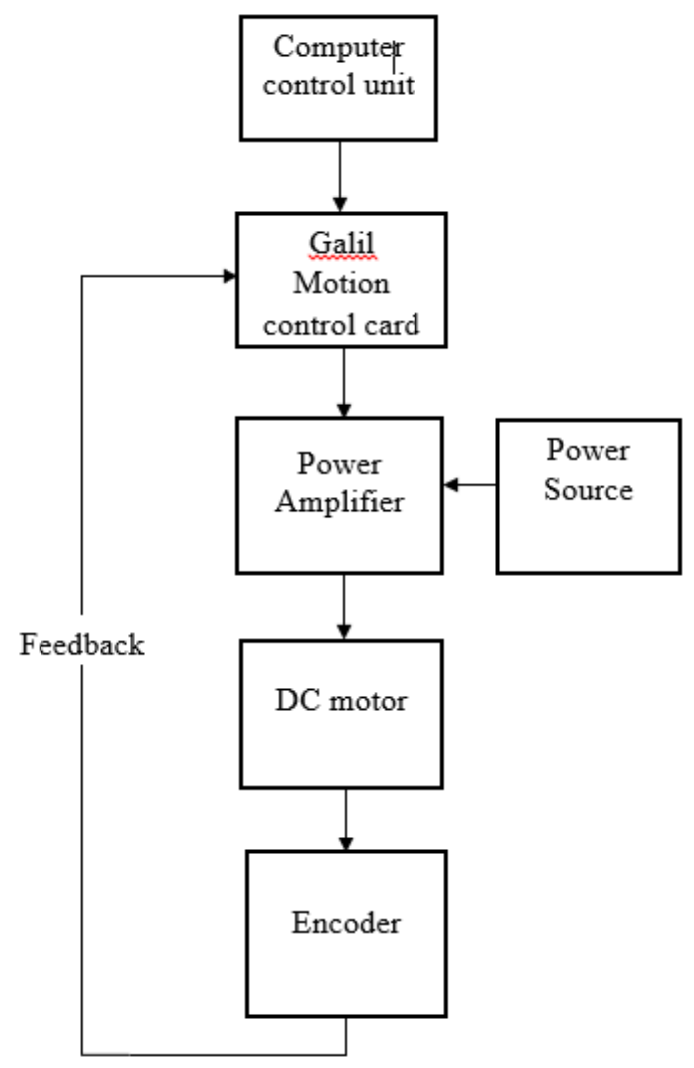

Figure 6 Control system unit flow chat

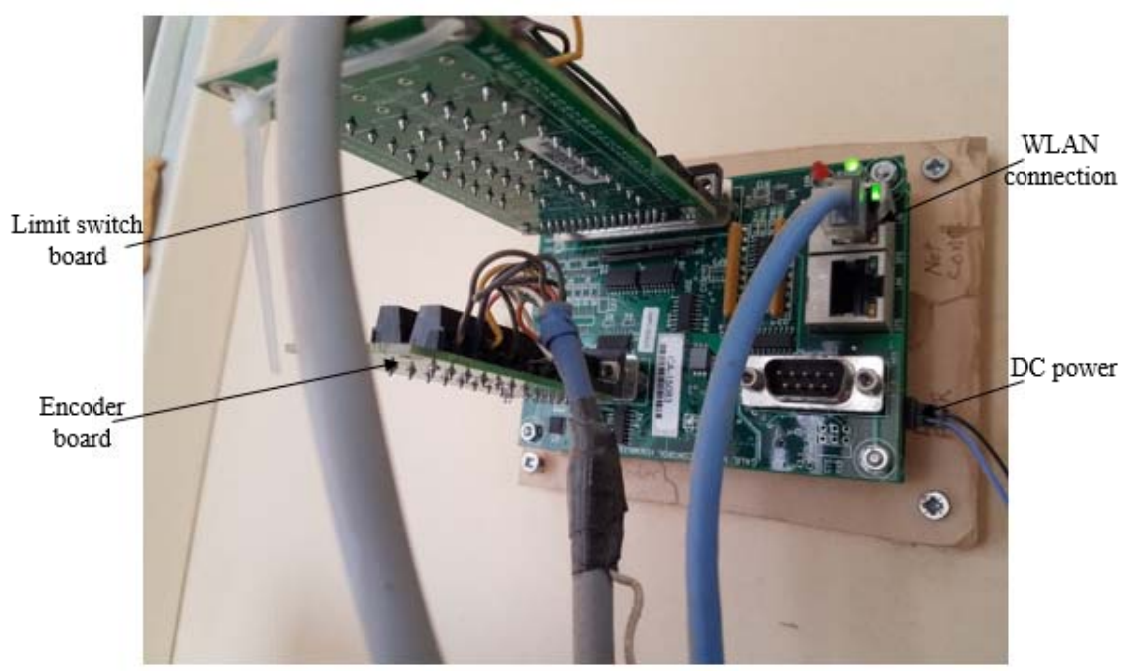

Figure 7 Galil DMC-3x01x single axis motion controller 


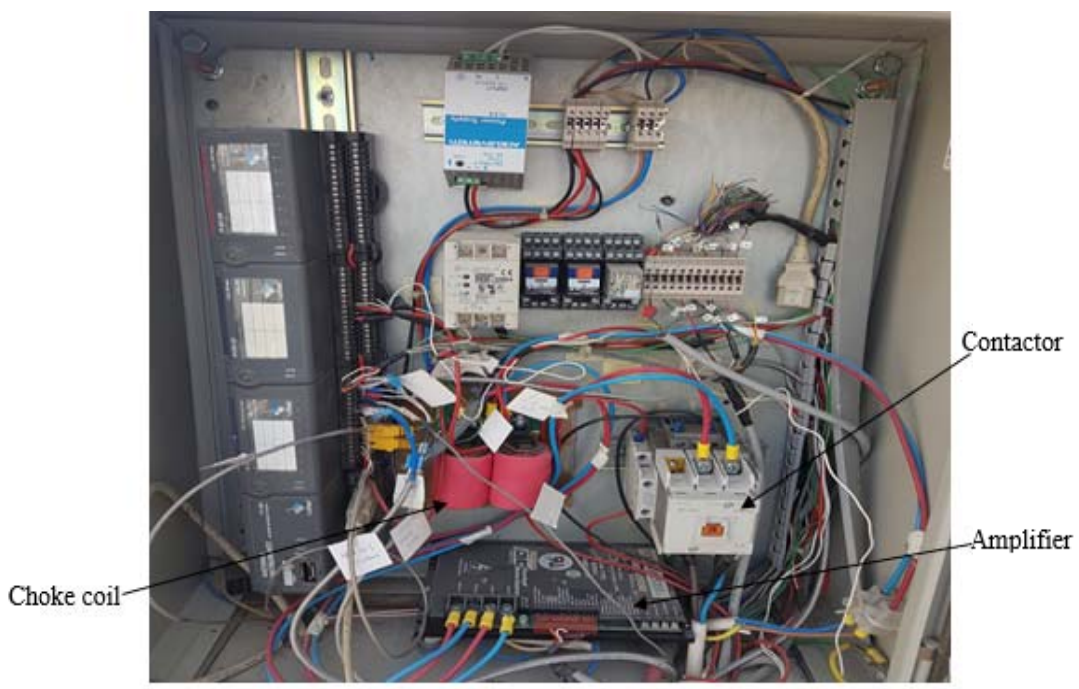

Figure 8 A 25A20 PWM servo amplifier connection with choke coil and contactor

Solar photovoltaic (PV) is designated as a method of transforming solar energy into direct current electricity by employing a semiconducting materials that display the photovoltaic effect. In other words, photovoltaic converters (solar cells) are semiconductor instruments that transforms part of the incident solar radiation directly into electrical energy [21]. The direct conversion of sunlight to electricity take place without any motion of parts or environmental discharges during operation.

Solar PV systems may be classified according to the end-use application of the technology. They are of two major types which are: Grid-connected (or grid-tied i.e. systems that supply power into the utility grid directly) and Off-grid (or stand-alone i.e. systems that charge batteries, maybe with the use of a generator back-up) solar PV systems. Since the purpose of the installed PV units on the PTC is to powers the entire system in case of unavailability of power from the national grid, it falls under the category of Off-grid solar PV.

The installed PV on the wings of the PTC can be seen in Fig. 1 above, they are 24 in number. The PV's are connected in such a way that, 3 numbers of the PV are connected in series with one another thereby making 8 numbers of 3 series connected PV's while the 8 numbers of PV's are now connected parallel to one another. This connection is influenced due to the voltage requirement of the entire system design.

The storage unit and charge controller/ inverter system is shown in Fig. 8. The charge controller/ inverter system does the conversion of AC to DC and vice versa while the storage unit as its name implies serves as a power storage unit so as to power the entire system in case of unavailability of power from the national grid.

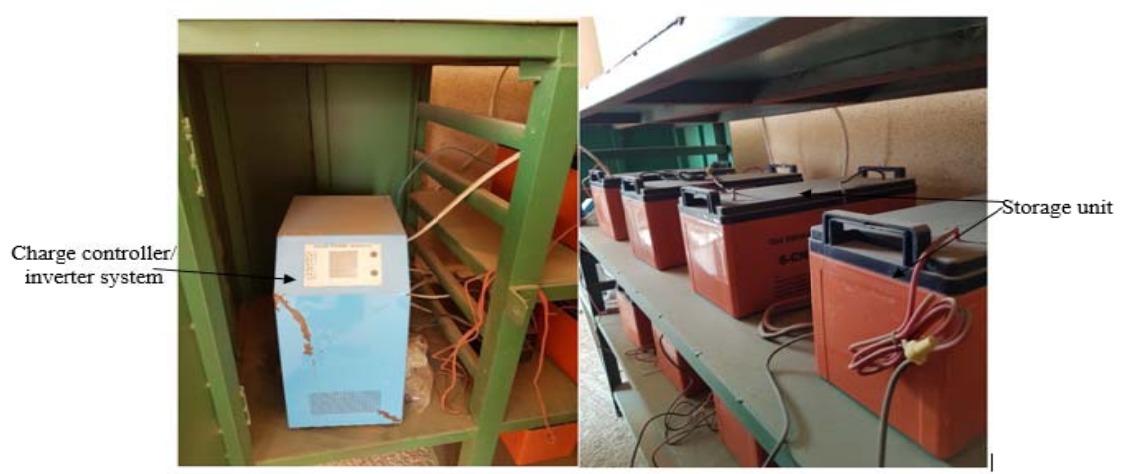

Figure 9 A storage unit and an Inverter system. 


\section{3) Sensing Devices}

The sensing devices used for the implementation of the solar tracking systems are limit switches, absolute type encoder and they are discussed below

\subsubsection{Limit switches}

Limit switches are installed in order serve as overall collector rotation restrictor and they are installed on both direction (i.e. the east and west direction).The three limit switches used for the design of the solar tracking system are the home, forward and return limit switches. As their name signifies the home limit switch senses the collector when it get to the home position and sends a signal to the control unit so as to stop the collector from moving beyond its rotational limits. The limit switches are shown in Fig. 9. It show a close view of the return limit switch and an expanded view of both the home, forward and return limit switches.

\subsubsection{Feedback}

An encoder (absolute type encoder) was used in this design to keep track of the angular position of the PTC. An absolute type was used because there is need to keep information of the previous position of the collector. The encoder was mounted on the shaft of the motor so as to measure the orientation of the solar tracker. Fig. 10 show the mounted encoder on the shaft of the DC motor.

The number of counts for one revolution of the encoder is equal to 4000 counts. Therefore $1^{\circ}$ movement of the encoder is equal to 11.111 counts and since the gear reduction of the chain drive mechanism is 6.667 from equation (14), and the speed reduction transmission system (worm speed reducer) gear ratio is 1:100. Therefore, the total reduction is 666.7 so that one turn of the motor gives $360 / 666.7$ degree at the collector axis, making $1^{\circ}$ movement of the PTC to be equivalent to 7407.333 counts of the encoder.

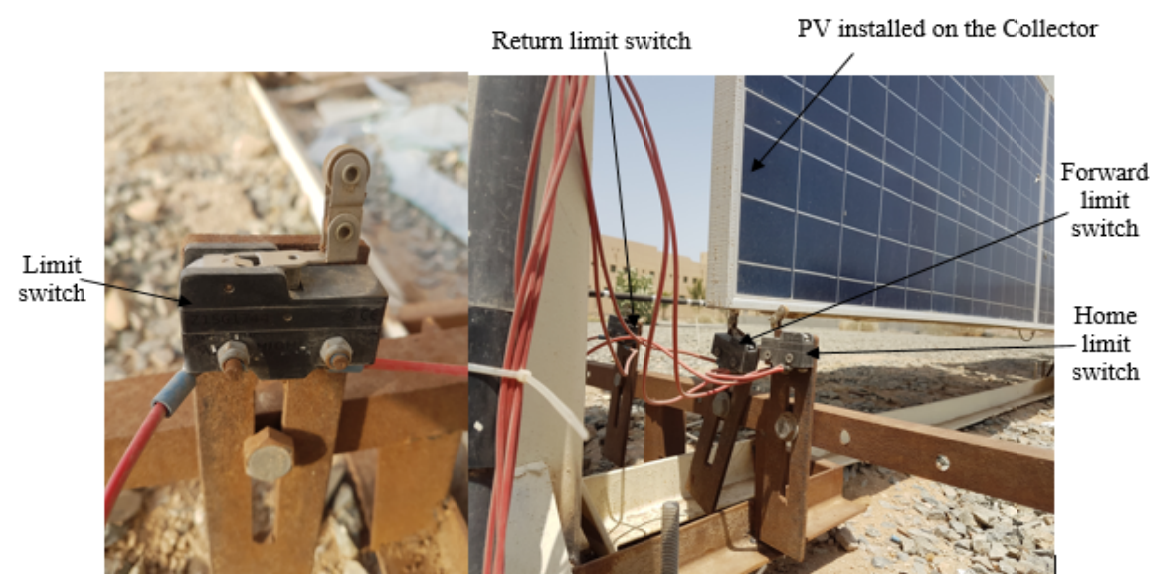

Figure 10 Installed limit switches at both ends of the collector axis

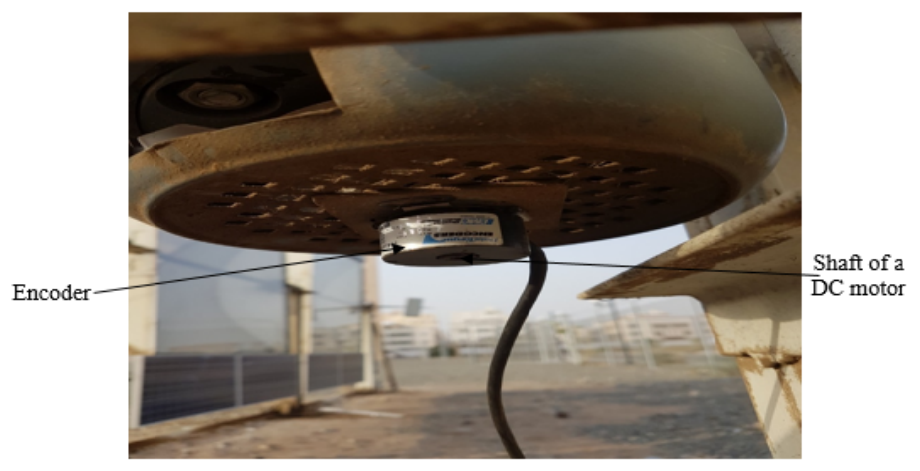

Figure 11 An encoder installed on the shaft of the DC motor

\section{Implementation of solar tracking algorithm}

The algorithm is designed based on a closed loop system as discussed in section 2.2. The flow chat for the sun tracking algorithm implementation is shown in Fig 12. 


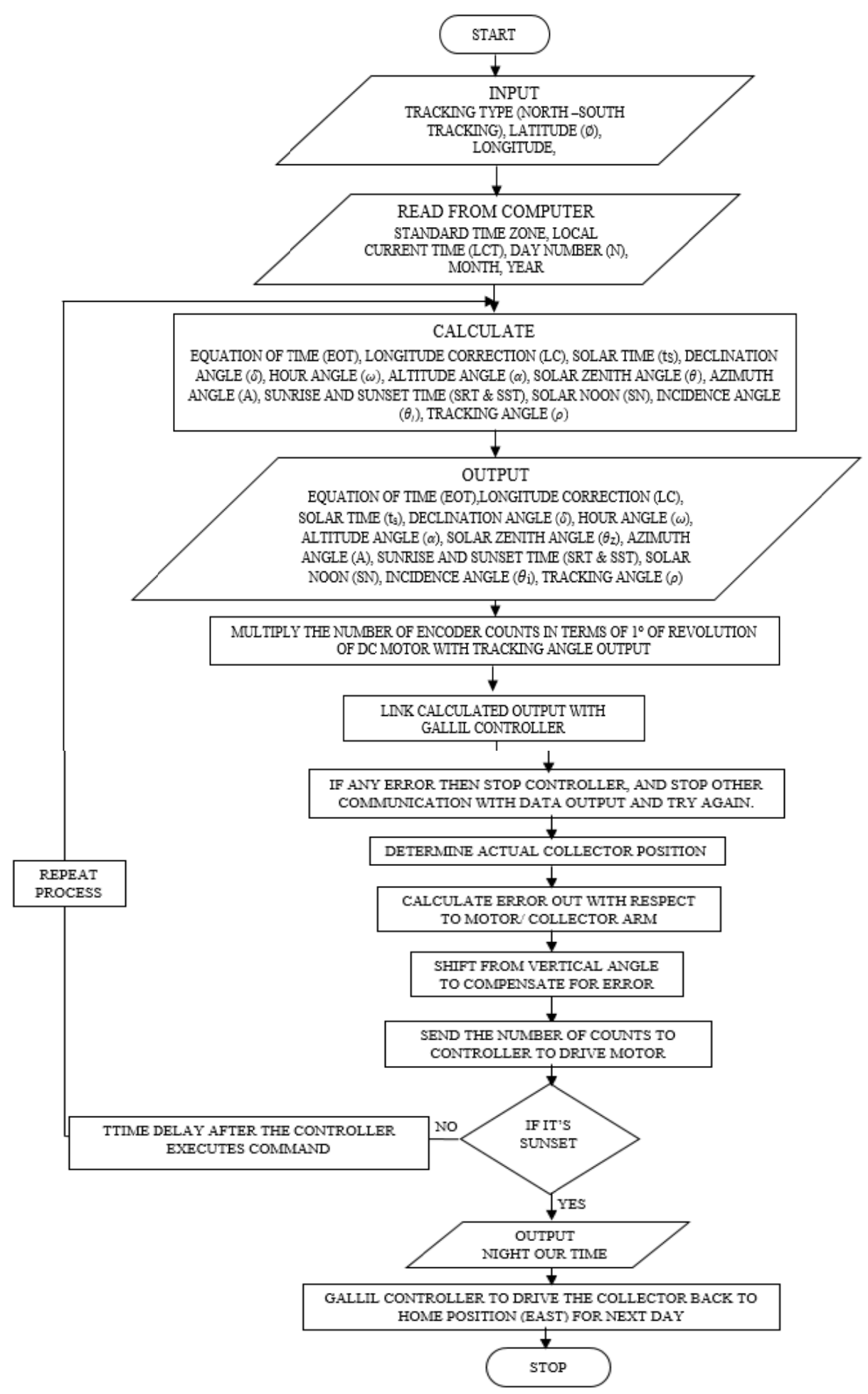

Figure 12 Sun tracking Algorithm

National Instrument LabView ${ }^{\circledR} 14$ was used for the implementation of the solar tracking algorithm in accordance to Fig. 12 and the front panel of the LabView ${ }^{\circledR}$ program main control can be seen in the Fig. 13. The LabView ${ }^{\circledR}$ program main control panel depends on each function of the LabView ${ }^{\circledR}$ program-subroutines (VI) as it was described by the sun tracking algorithm. 


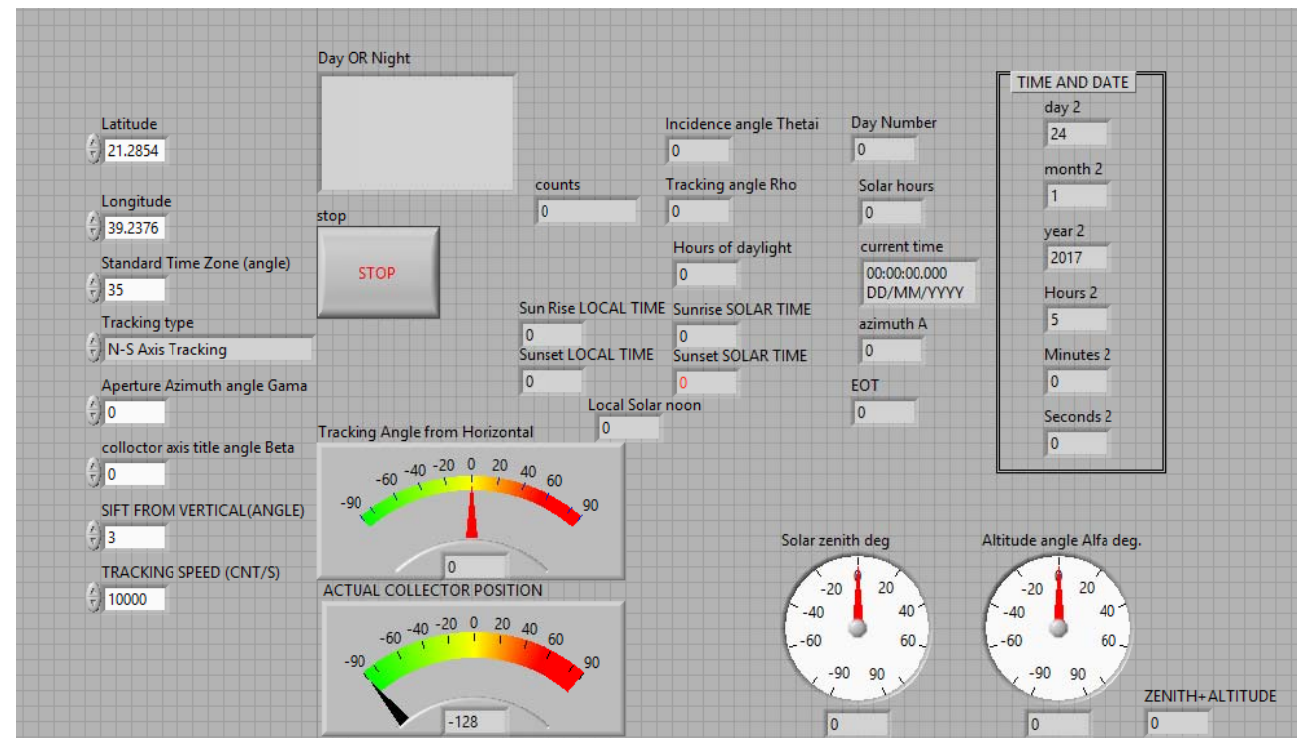

Figure 13 The front panel of the LabView program-subroutines for the designed solar tracker

\section{D) Performance estimation}

The tracking system is mainly judged by the amount of error it introduce it to perfectly track the sun. Mathematically speaking, this error will depend only on the time delay between each update to the controller with new angle. If the update rate is high and limited only by the time of calculations and the speed and power of the tracking motor, we can safely conclude that there is no error that could affect the performance of the collector in harvesting thermal solar energy. On the other hand, this situation will put more load on the tracking system components. To evaluate the effect of introducing certain time delay between each update to the controller, Fig. 15 shows half of the parabola with two sun beams. One is normal to the collector aperture and the other is deviated by an error of $\Delta \rho$. The $\Delta \rho$ is the error in tracking angle due to the time delay between two updates $\Delta \mathrm{t}$. The $\Delta \rho$ is dependent on both $\Delta \mathrm{t}$ and the time during the sun hours. In fig. 15 the sun half angle is shown. This half angle determines how much of the incoming sun rays will intercept the receiver tube. Fig. 15 shows the maximum error allowed where the intercepted rays are just tangent to the bottom of the receiver. So, this position will be analysed to find out the maximum time delay that can be used on the tracking algorithm.

During the time delay the collector is kept stationary on last update. But the sun is continuously moving. So, it is required at each time of day light the tracking angle to be calculated. Assuming that the speed of the tracking motor is high relative to the speed of the sun movement in the sky. That impose that when the new tracking angle is updated the collector will go to that position at no time.

The rate of change of the tracking angle can obtained by differentiating the previous relations of the inclination angle and the Azimuth then substituting in the rate of change of the tracking angle as follows:

$$
\frac{d \rho}{d t}=\frac{\cos \alpha \cos A \frac{d A}{d t}-\left((\sin \alpha)^{2} \sin A+\sin A \cos \alpha^{2}\right) \frac{d \alpha}{d t}}{\left(1+\tan \rho^{2}\right) \sin \alpha^{2}}
$$

where

$$
\begin{gathered}
\frac{d \alpha}{d t}=\frac{-\cos \varphi \sin \delta \sin \omega}{\cos \alpha} \frac{d \omega}{d t} \\
\frac{d A}{d t}=\frac{\cos \delta}{\cos A \cos \alpha^{2}}\left(\cos \delta \sin \omega^{2} \tan \alpha \cos \varphi-\cos \alpha \cos \omega\right) \frac{d w}{d t} \\
\frac{d \omega}{d t}=\text { constant }=15 \mathrm{deg} / \quad
\end{gathered}
$$




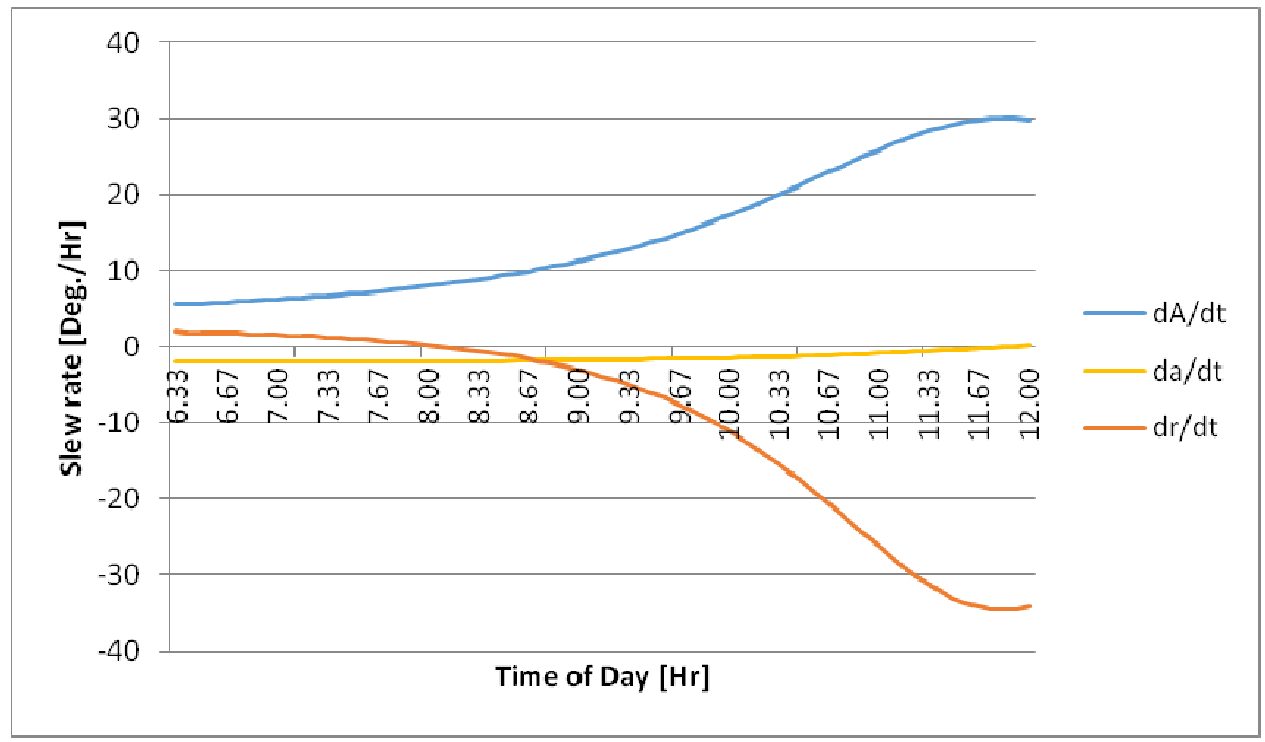

Figure 14 Variation in the rate at which the solar azimuth and altitude angles change for three representative days. The latitude is 21.2854 DEGREE and longitude 39.2376 DEGREE. 1st March.

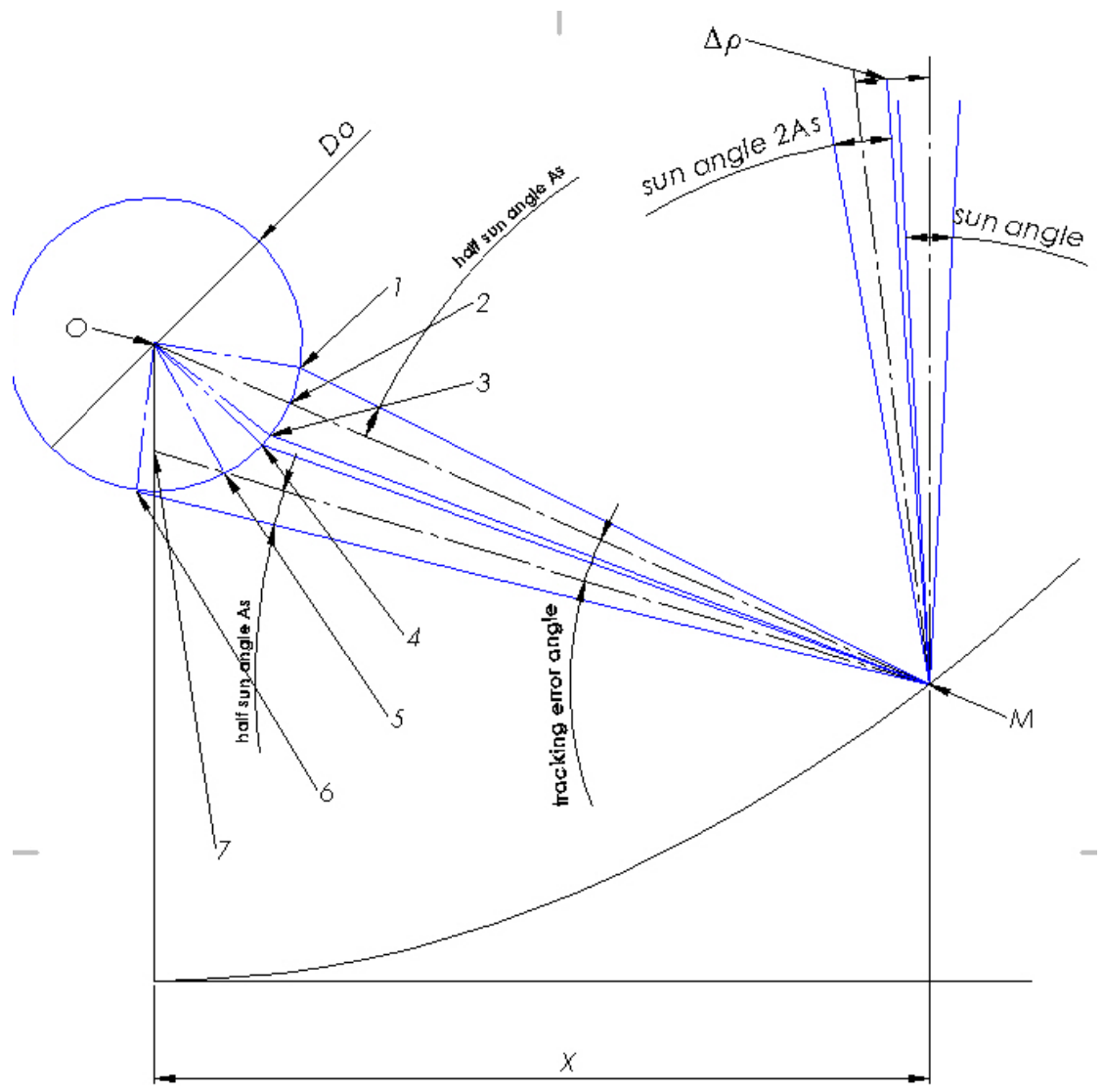

Figure 15 The geometrical diagram of a parabolic trough collector with two beams with half sun angles: points 1, 2, and 3 defines the correct tracking position intercept. Points 4, 5, and 6 defines the deviated tracking position intercept where point 6 is the tan 
Table II. GeOMETRICAL PARAMETERS OF THE PARABOLIC TROUGH COLLECTOR [23].

\begin{tabular}{|c|c|c|}
\hline Parameters & Symbols & Dimension (mm) \\
\hline Height of the parabola & $\mathrm{h}$ & 490 \\
\hline Focal length & $\mathrm{f}$ & 404 \\
\hline Trough length & $\mathrm{l}$ & 1720 \\
\hline width & $w_{a}$ & 1693.5 \\
\hline Length of parabolic arc & $\mathrm{s}$ & 1965.5 \\
\hline Absorber tube outer diameter & $\mathrm{D}$ & 42 \\
\hline Glass cover thickness & $\mathrm{t}$ & 4 \\
\hline Reflector thickness & $\mathrm{J}$ & 0.5 \\
\hline Geometric concentration ratio & $\mathrm{c}$ & 12.83 \\
\hline Rim angle & $\varphi_{r}$ & $92.63^{\circ}$ \\
\hline Reflectance of the reflector & $\epsilon$ & 0.95 \\
\hline Transmittance of the glass cover & $\tau$ & 0.90 \\
\hline Absorptance of the receiver & $\alpha$ & 0.97 \\
\hline Rim radius & $r_{r}$ & 847.7 \\
\hline Acceptance angle & $\theta_{m}$ & $2.84^{\circ}$ \\
\hline
\end{tabular}

the parabola equation is

$\mathrm{y}=\frac{1}{4 \mathrm{f}} \mathrm{x}^{2}(19)$

where $\mathrm{f}$ is the focal length $=404 \mathrm{~mm}$

Using trigonometry on the Fig. 15 above and table 1, the following could be obtained:

$\mathrm{OM}=\sqrt{\left(\mathrm{f}-\mathrm{y}_{\mathrm{M}}\right)^{2}+\left(\frac{\mathrm{w}}{2}\right)^{2}}=847 \mathrm{~mm}$

Where $\mathrm{yM}=\mathrm{y}$ coordinate of point $\mathrm{M}=443.6 \mathrm{~mm}$ which is above the focal point.

$\mathrm{W}=$ Parabola width $=1693.5 \mathrm{~mm}$ in our case

Do $=$ receiver tube diameter $=42 \mathrm{~mm}$

Then,

$\overline{\mathrm{M} 6}=\overline{\mathrm{OM}} \sin (\mathrm{OM} 6)$

where the angle $0 \mathrm{M} 6=\mathrm{A}_{\mathrm{S}}+\Delta \rho$

Assume As $=.525 / 2$ degree

then $0 \mathrm{M} 6=\sin ^{-1} \frac{\overline{\mathrm{M} 6}}{\overline{\mathrm{OM}}}=.116$ degrees

Then $\Delta \rho=\left|0 M 6-\mathrm{A}_{\mathrm{S}}\right|=0.15$ degree

So this value is maximum error to maintain the full rays intercept the receiver tube.

Fig. 16 shows the error variation through the day 1 st of march at different time delay. from that figure it is clear that the maximum time dely can be used to maintain nearly zero error is 30 seconds. 


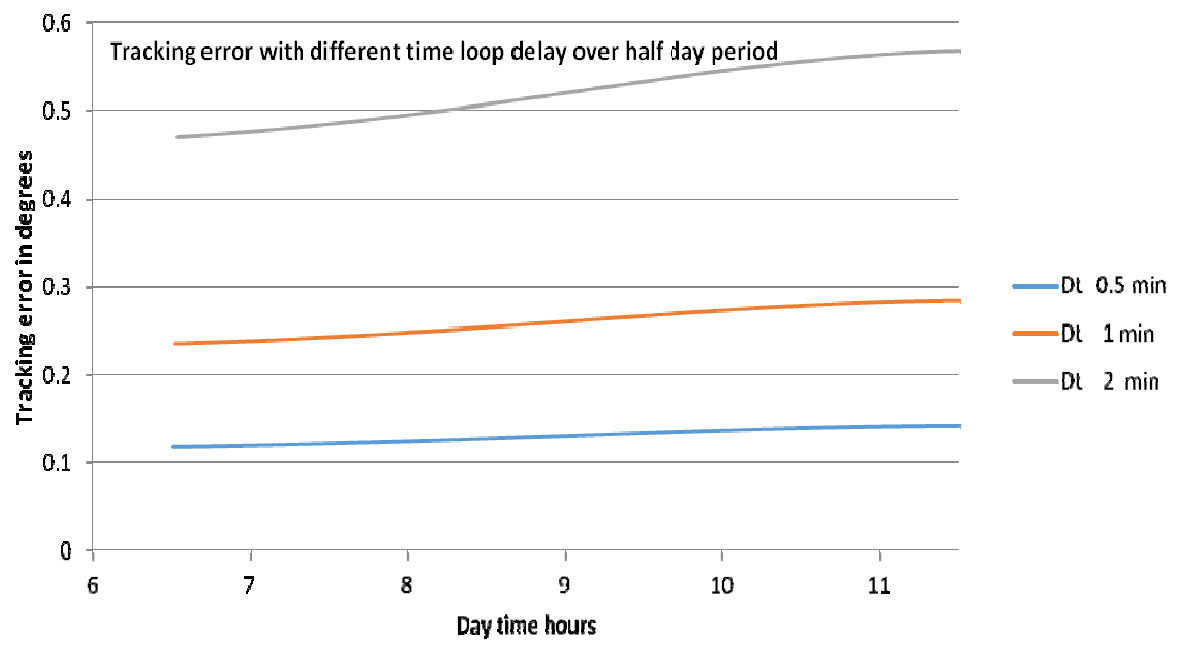

Figure 16 variation of the tracking error at different time delay

\section{CONCLUSION}

The algorithm which was designed based on a closed loop system and implemented with National Instrument LabView in collaboration with Galil DMC-3x01x single axis motion controller were used to successfully drive the six series connected PTC to track the motion of the sun from sunrise to sunset with minimal error estimation.

\section{ACKNOWLEDGMENT}

This project was funded by the National Plan for Science, Technology and Innovation (MAARIFAH) - King Abdulaziz City for Science and Technology - the Kingdom of Saudi Arabia - award number (11-ENE2004-03). The authors also acknowledge with thanks, Science and Technology Unit, King Abdulaziz University for their technical support.

\section{REFERENCE}

[1] Chia-Yen Lee, Po-Cheng Chou, Che-Ming Chiang, Chiu-Feng Lin; Sun Tracking Systems: A Review, Sensors 2009, 9, pp 3875-3890;

[2] Shahriar Bazyari, Reza Keypour, Shahrokh Farhangi, Amir Ghaedi, Khashayar Bazyari; A Study on the Effects of Solar Tracking Systems on the Performance of Photovoltaic Power Plants, Journal of Power and Energy Engineering, 2014, 2,pp 718-728

[3] Asst. Prof. Narendrasinh .J. Parmar, Ankit .N. Parmar, Vinod .S. Gautam; Passive Solar Tracking System, International Journal of Emerging Technology and Advanced Engineering; Volume 5, Issue 1, January 2015

[4] Steven Bushong; Advantages and disadvantages of a solar tracker system, Solar FlexRack; 2016

[5] McFee, R.H; Power collection reduction by mirror surface non-flatness and tracking error for a central receiver solar power system. Appl. Opt. 1975, 14, pp 1493-1502.

[6] Semma, R. P, Imamura, M. S; Sun tracking controller for multi-kW photovoltaic concentrator system, In Proceedings of the 3rd International Photovoltaic Sol Energy Conference, Cannes, France, Oct. 27-31, 1980.

[7] Stone, K.W, Sutherland J.P; Solar two heliostat tracking performance, In Proceedings of International Solar Energy Conference, Washington DC, USA, Apr. 1997, pp 27-30.

[8] Khalifa A.N, Al-Mutawalli S.S; Effect of two-axis sun tracking on the performance of compound parabolic concentrators, Energy Conversion Management 1998, 39, pp 1073-1079.

[9] Yousef, H.A; Design and implementation of a fuzzy logic computer-controlled sun tracking system, In Proceedings of IEEE International Symposium on Industrial Electronics, Bled, Slovenia, Jul. 1999, pp 12-16.

[10] Roth, P, Georgieg, A, Boudinov, H; Design and construction of a system for sun-tracking, Renewable Energy 2004, 29, pp 393-402.

[11] Allen-Bradley, Rockwell software; Solar Tracking Application, www.rockwellautomation.com,February 2011

[12] Binoy Seal, Omkar Shirke, Siddhesh Shewale, Abhilash Sirsikar, Prof.Priya Hankare; Comparision Between Different Solar Tracking System and Wireless Technology, International Journal of Advanced Research in Computer Science and Software Engineering, Volume 4, Issue 4, April 2014

[13] Bin-Juine Huang, Yin-Chen Huang, Guan-Yu Chen, Po-Chien Hsu, Kang Li; Improving Solar PV System Efficiency Using One-Axis 3-Position Sun Tracking, Energy Procedia, 2013, pp. 280 - 287

[14] Yingxue Yao, Yeguang Hu, Shengdong Gao, Gang Yang, Jinguang Du; A multipurpose dual-axis solar tracker with two tracking strategies, Renewable Energy, 2014, pp. 88-98

[15] Laughlin Barker, Matthew Neber, Hohyun Lee; Design of a low-profile two-axis solar tracker, Solar Energy, 2013, pp. 569-576

[16] Wikipedia, en.m.wikipedia.org/wiki/Jeddah, 2017.

[17] Lamm, L. O; A New Analytic Expression for the Equation of Time, Solar Energy 26 (5), 1981, pp. 465.

[18] Soteris Kalogirou; Solar energy engineering - processes and systems, Elsevier Inc. 1st ed.2009.

[19] Prinsloo, G.J., Dobson, R.T. Solar Tracking: High precision solar position algorithms, programs, software and source-code for computing the solar vector, solar coordinates \& sun angles in Microprocessor, PLC, Arduino, PIC and PC-based sun tracking devices or dynamic sun following hardware. Stellenbosch: SolarBooks. 2015, p 1-542.

[20] Stine, W.B. and Geyer, M; Power from the Sun, Published online by William B. Stine and

[21] Michael Geyer. 2001.

[22] John A. Duffie, William A. Beckman; Solar Engineering of Thermal processes, Fourth Edition, John Wiley \& Sons, Inc., 2013 , pp 745

[23] Faissal Abdel-Hady, Saani Shakil, Mostafa Hamed, Abdulrahim Alzahrani, Abdel-Hamid Mazher; Design, simulation and manufacturing of an integrated composite material parabolic trough solar collector, International Journal of Engineering and Technology (IJET), Vol 8 No 5,2016. 


\section{AUTHOR PROFILE}

Faissal Abdel-Hady joined the Department of Chemical \&Materials Engineering at King Abdulaziz University in 2009. He received his BS and MS degrees from Ain Shams University, Cairo, Egypt in 1975 and 1985, respectively. He received his Ph.D. in Mechanical Engineering from mutual cooperation between Ain Shams University, Egypt and Ecole des Mines de Saint Etienne, France. During the period 1999-2006 he was Senior Research Fellow at Auburn University, Alabama, USA. During that period he worked for NASA in developing energy storage system for the new space shuttle. He was associate professor at Bemidji State University, Minnesota, USA, from 2006 to 2009. 